\title{
Analysis of residual stresses induced by dry turning of difficult-to-machine materials
}

\author{
J.C. Outeiro ${ }^{\mathrm{a}, \mathrm{b}, *}$, J.C. Pina $^{\mathrm{b}}$, R. M'Saoubi $(2)^{\mathrm{c}}$, F. Pusavec ${ }^{\mathrm{d}}$, I.S. Jawahir (1) ${ }^{\mathrm{d}}$ \\ ${ }^{a}$ Faculty of Engineering, Portuguese Catholic University, Lisbon, Portugal \\ ${ }^{\mathrm{b}}$ CEMDRX, Department of Physics, FCTUC, University of Coimbra, Coimbra, Portugal \\ ${ }^{\mathrm{c}}$ Seco Tools AB, Fagersta, Sweden \\ d Machining Research Laboratory, Center for Manufacturing, Department of Mechanical Engineering, University of Kentucky, Lexington, USA
}

\section{A R T I C L E I N F O}

\section{Keywords:}

Modelling

Machining

Residual stresses

\begin{abstract}
A B S T R A C T
Critical issues in machining of difficult-to-cut materials are often associated with short tool-life and poor surface integrity, where the resulting tensile residual stresses on the machined surface significantly affect the component's fatigue life. This study presents the influence of cutting process parameters on machining performance and surface integrity generated during dry turning of Inconel 718 and austenitic stainless steel AISI 316L with coated and uncoated carbide tools. A three-dimensional Finite Element Model was also developed and the predicted results were compared with those measured.
\end{abstract}

(C) 2008 CIRP.

\section{Introduction}

The quality and performance of a machined component are directly related to surface integrity, which includes the topological parameters (surface roughness and other characteristic surface topographic features), mechanical properties (residual stresses, hardness, etc.), and metallurgical states of the work material during processing (phase transformation, microstructure and related property variations, etc.). Various means of assessing surface and sub-surface integrity are well established [1]. Compressive residual stresses are usually aimed at the machined surface and the sub-surface, as they increase the fatigue life [2].

Residual stress is one of the most relevant practical parameters used for evaluating the quality of the machined surface, particularly when critical structural components are machined, with the objective to reach the high reliability levels. This is the case for the components made from austenitic stainless steels and Inconel alloys, which are largely used in nuclear power generation and aerospace industries. These two alloys are considered difficultto-machine due to their inherent mechanical and thermal properties posing difficulty for machining. Both alloys have high mechanical properties and exhibit severe work hardening, combined with low thermal conductivity. As a consequence, high cutting forces are produced along with high localized temperatures around the cutting edge, and on the machined surface, thus producing high tensile residual stress levels (sometimes reaching over $1000 \mathrm{MPa}$ at the component's machined surface).

The residual stresses induced by machining AISI 316L steel are usually highly tensile on the machined surface, and these stresses decrease at a high rate in-depth direction, reaching a maximum compressive residual stresses in the sub-surface layer [3,4]. The

\footnotetext{
* Corresponding author.
}

residual stresses induced by machining Nickel-based alloys, such as Inconel 718, are even more critical, due to safety and sustainability concerns. This material is largely used in aeronautic/aerospace industry to produce aero-engine components due to its ability to withstand high loadings under very aggressive environments (high temperatures, corrosion, etc.). The surface residual stresses induced by machining such alloys are also tensile, and are of the same order of magnitude, or sometimes even higher than those residual stresses induced by machining AISI 316L steel $[5,6]$.

Although much of the past surface integrity studies on machining of these materials have been focusing on the experimental analysis of the effects of cutting parameters, tooling geometry and machining media, etc., on machining-induced residual stresses [2-6], in recent years, attempts are also being made to develop predictive models for surface integrity using analytical methods [7] and finite element simulations [8,9].

In the present investigation, the residual stresses induced by dry turning AISI 316L steel and Inconel 718 alloy using coated and uncoated cemented carbide tools are studied and discussed.

\section{Experimental and numerical procedures}

\subsection{Work materials, cutting tools and cutting parameters}

Round bars of Austenitic steel AISI 316L and Inconel 718 (solution-treated and age-hardened) alloy were selected for this study. The cutting tools consisted of uncoated and PVD coated (TiAlN-2 $\mu \mathrm{m}$ ) cemented carbide tools. The selected cutting parameters and the tool geometry are summarized in Table 1. T1 tool geometry (coated and uncoated tools) was used for machining Inconel 718 alloy, while the T2 tool geometry (only uncoated tool) was used for machining the AISI 316L steel. All the tests were conducted under dry cutting conditions. 
Table 1

Tool geometry and cutting parameters (C-coated; U-uncoated)

\begin{tabular}{llc}
\hline & $T 1(\mathrm{C}, \mathrm{U})$ & $T 2(\mathrm{U})$ \\
\hline Tool cutting edge radius, $r_{\mathrm{n}}(\mu \mathrm{m})$ & 25 & 44 \\
Tool nose radius, $r_{\varepsilon}(\mathrm{mm})$ & 0.8 & 0.8 \\
Normal rake angle, $\gamma_{\mathrm{n}}\left(^{\circ}\right)$ & -6 & -4.29 \\
Normal flank angle, $\alpha_{\mathrm{n}}\left({ }^{\circ}\right)$ & 6 & 4.29 \\
Inclination angle cutting edge, $\lambda_{\mathrm{s}}\left(^{\circ}\right)$ & -6 & -14 \\
Tool cutting edge angle, $\kappa_{\mathrm{r}}\left(^{\circ}\right)$ & 95 & 72 \\
Tool minor cutting edge angle, $\kappa_{\mathrm{r}}^{\prime}\left(^{\circ}\right)$ & 5 & 72 \\
Cutting speed, $\nu_{\mathrm{c}}(\mathrm{m} / \mathrm{min})$ & $55 ; 70$ & 125 \\
Feed, $f(\mathrm{~mm} / \mathrm{rev})$ & $0.15 ; 0.2$ & 0.05 \\
Depth of cut, $a_{\mathrm{p}}(\mathrm{mm})$ & 0.5 & 2.5 \\
\hline
\end{tabular}

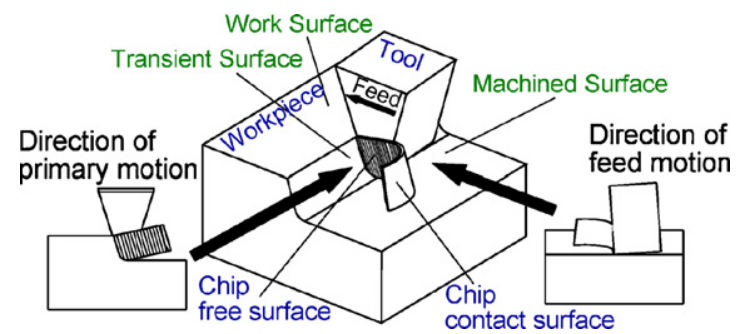

Fig. 1. Representation of the planes used in the IR based temperature measurements.

\subsection{Experimental set-up and parameters}

Turning tests were performed on a modern CNC lathe equipped with a specially designed experimental set-up for cutting forces and Infrared temperature measurement. A detailed description of this equipment and calibration procedures are previously described in [10]. The thermal measuring system was installed on the lathe to allow the measurement of the temperature fields in the direction of primary motion and in the direction of feed motion as shown in Fig. 1.

The residual stress state in the transient and machined surfaces and sub-surface has been analyzed by the X-ray diffraction technique using the $\sin ^{2} \psi$ method [11]. The parameters used in the X-ray analysis of the two materials are shown in Table 2. Residual stresses were determined in the transient and machined surfaces and the sub-surface, in the direction of primary motion $\left(\sigma_{\|}\right)$and in the direction of feed motion $\left(\sigma_{\perp}\right)$. To determine the indepth residual stress profiles, successive layers of material were removed by electropolishing, thus avoiding the reintroduction of additional residual stresses. Further corrections to the data were made for the volume of the material removed.

\subsection{Numerical model and parameters}

The commercial FEA software DEFORM-3D ${ }^{\mathrm{TM}}$ version 6.1 , a Lagrangian implicit code, was used to simulate the threedimensional cutting process of Inconel 718 alloy and AISI 316L steel. A finite element model was developed for the turning operation, and this was composed of the workpiece and tool, as shown in Fig. 2. The workpiece was initially meshed with 180000 isoparametric quadrilateral elements, while the tool was modelled as rigid.

A plane-strain coupled thermo-mechanical analysis was performed. To model the thermo-elasto-viscoplastic behaviour

Table 2

Parameters used in the X-ray analysis

\begin{tabular}{|c|c|c|}
\hline Work material & AISI 316L & Inconel 718 \\
\hline Young's modulus (GPa) & 196 & 196 \\
\hline Poisson ratio & 0.28 & 0.31 \\
\hline Radiation & $\mathrm{Mn} \mathrm{K} \alpha$ & $\mathrm{Mn} \mathrm{K} \alpha$ \\
\hline Bragg angle $2 \theta\left(^{\circ}\right)$ & $146.01(h k l)=\left(\begin{array}{lll}3 & 1 & 1\end{array}\right)$ & $152.26(h k l)=\left(\begin{array}{lll}3 & 1 & 1\end{array}\right)$ \\
\hline Number of $\psi$ angles & 13 & 15 \\
\hline$\psi$ tilt $\left(^{\circ}\right)$ & 5 & 3 \\
\hline
\end{tabular}

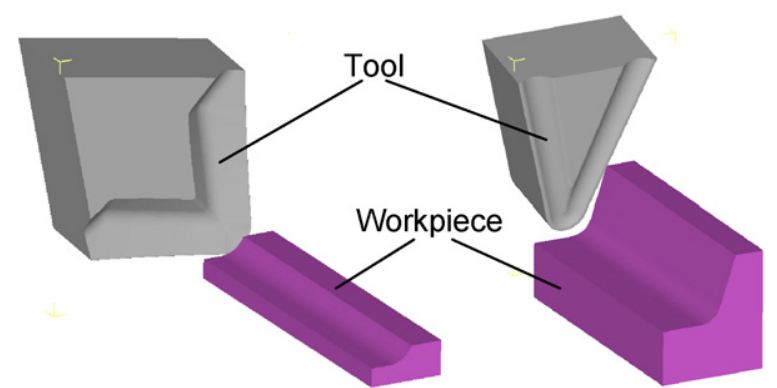

Fig. 2. FE geometry of the turning operation (left-T1 tool geometry; right-T2 tool geometry).

of Inconel 718 alloy, the data presented in Deform database was used. To model the elastic behaviour of AISI 316L steel, the data presented in [12] was used. To model the thermo-viscoplastic behaviour of AISI 316L steel, a Johnson-Cook's constitutive equation was employed for which the material constants were selected from an earlier study [8]. The physical properties of the Inconel 718 and AISI 316L steels, and the thermal conductivities of the cutting tool inserts are given in Deform database and in an earlier publication [6]. Concerning the tribological characteristics of the tool-chip and tool-workpiece interfaces, a simple model, based on the constant shear factor, $s\left(\tau=s \tau_{0}\right)$, together with a constant heat transfer coefficient, $h=100 \mathrm{~kW} / \mathrm{m}^{2} \mathrm{~K}$, were used in the simulations [9]. The value of $s$ was calculated using the measured cutting forces, being equal to 0.6 for the uncoated and 0.4 for the coated tools.

\section{Results and discussion}

\subsection{Comparison between predicted and measured forces and temperatures}

Simulated and measured cutting forces and temperatures were compared. This procedure was applied for both work materials: for the case of AISI 316L steel in machining with uncoated tool at $v_{\mathrm{c}}=125 \mathrm{~m} / \mathrm{min}, f=0.05 \mathrm{~mm} / \mathrm{rev}$ and $a_{\mathrm{p}}=2.5 \mathrm{~mm}$, and for the case of Inconel 718 alloy in machining with coated tool at $v_{\mathrm{c}}=70 \mathrm{~m} / \mathrm{min}, f=0.2 \mathrm{~mm} / \mathrm{rev}$ and $a_{\mathrm{p}}=0.5 \mathrm{~mm}$.

The comparison of measured and simulated average force components show that the difference between the measured and simulated values of cutting force component $\left(F_{\mathrm{c}}\right)$ is small (less than $5 \%$ ), but a significant difference is seen for the feed force $\left(F_{\mathrm{f}}\right)$ and the radial force $\left(F_{\mathrm{p}}\right)$ components.

Fig. 3 shows the measured and simulated temperature distributions on the chip free surface (in the direction of primary motion), when machining AISI 316L steel. The maximum temperature, which is reached at the tool-chip interface, could not be measured by the infrared thermal imaging equipment. According to the simulations, this temperature is about $700{ }^{\circ} \mathrm{C}$. Moreover, the maximum measured temperature on the chip free surface is located at the chip root, closer to the tool nose radius and is about $600{ }^{\circ} \mathrm{C}$, which is in agreement with the simulations. It was however difficult to measure the temperature on the machined surface due to the limitations in measurement for 3D machining [10].

\subsection{Residual stresses in machining Inconel 718}

Experimentally measured residual stresses $\left(\sigma_{\|}\right.$and $\left.\sigma_{\perp}\right)$ induced in dry turning of Inconel 718 show the consistency of the measured residual stresses at different locations (from $0^{\circ}$ to $315^{\circ}$ ) along the circular profile of the machined bar, indicating that an average $\sigma_{\|}$ residual stress is about $120 \mathrm{MPa}$ higher than the average $\sigma_{\perp}$ residual stress (Fig. 4).

Figs. 5 and 6 show the in-depth residual stress profiles induced by machining with coated and uncoated cutting tools. Residual stresses are tensile at surface and gradually shift to compressive 


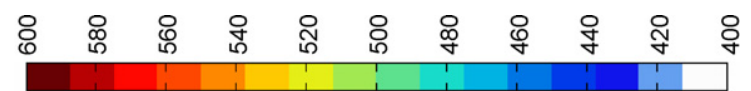

(a)
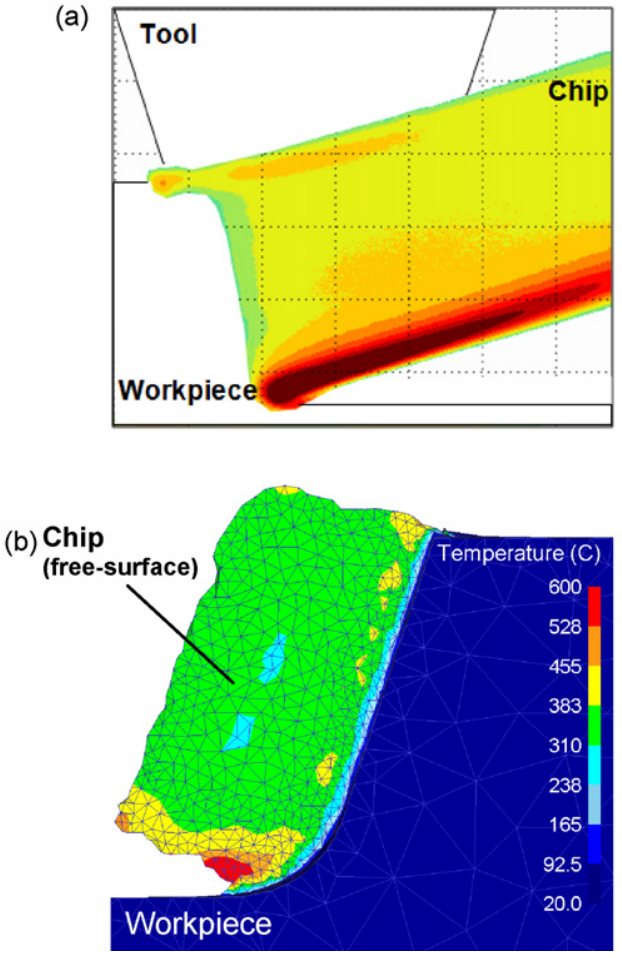

Fig. 3. Experimental (a) and simulated (b) thermal maps in turning AISI 316L.

values beneath the surface before stabilizing at the level corresponding to that found in the work material before machining (around zero MPa). For the range of cutting conditions investigated, the residual stresses were tensile and higher (reaching over $1000 \mathrm{MPa}$ at the machined surface) in the direction of primary motion (Fig. 5). These figures also show that machining with uncoated tools when compared with the coated tools results in: (i) higher surface ( $\sigma_{\|}$and $\sigma_{\perp}$ ) residual stresses; (ii) lower thickness of tensile layer; and (iii) lower residual stresses (maximum) in the sub-surface, with the maximum being shifted closer to the surface in machining with uncoated tools.

Using the hole drilling technique to measure the residual stresses, Sharman et al. [6] show that machining with coated tools,

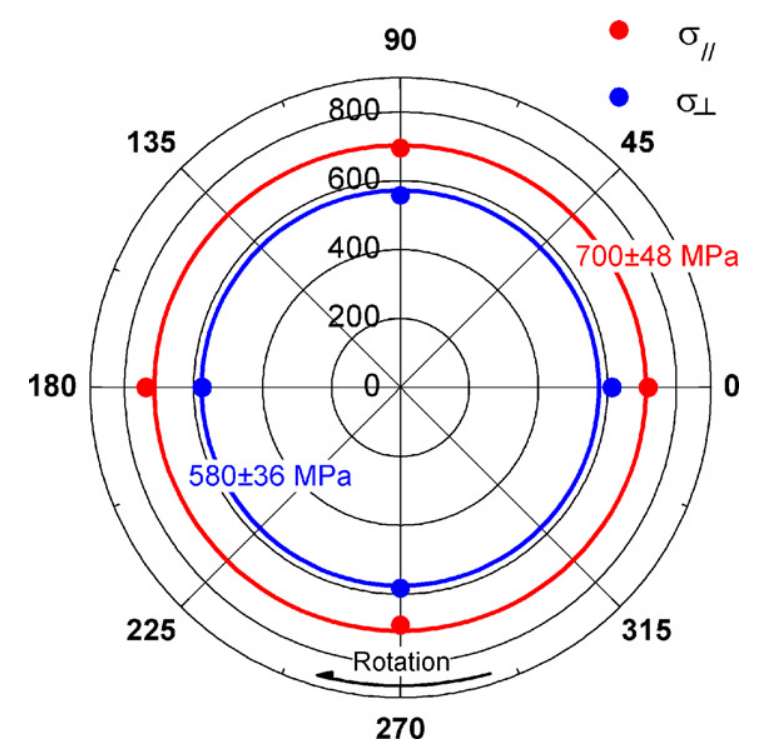

Fig. 4. Experimental residual stresses on the machined surfaces at different locations (Inconel 718; T1-coated tool; $v_{\mathrm{c}}=70 \mathrm{~m} / \mathrm{min}, f=0.2 \mathrm{~mm} / \mathrm{rev}$ and $\left.a_{\mathrm{p}}=0.5 \mathrm{~mm}\right)$.

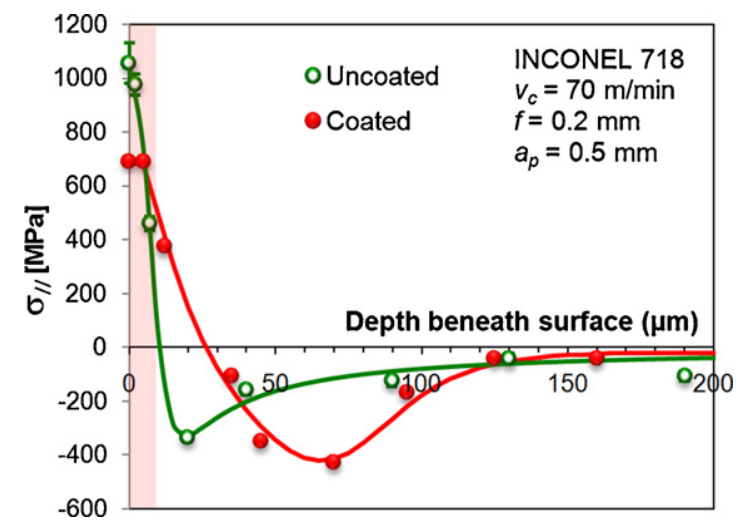

Fig. 5. In-depth $\sigma_{\|}$residual stress distribution in machining Inconel 718.

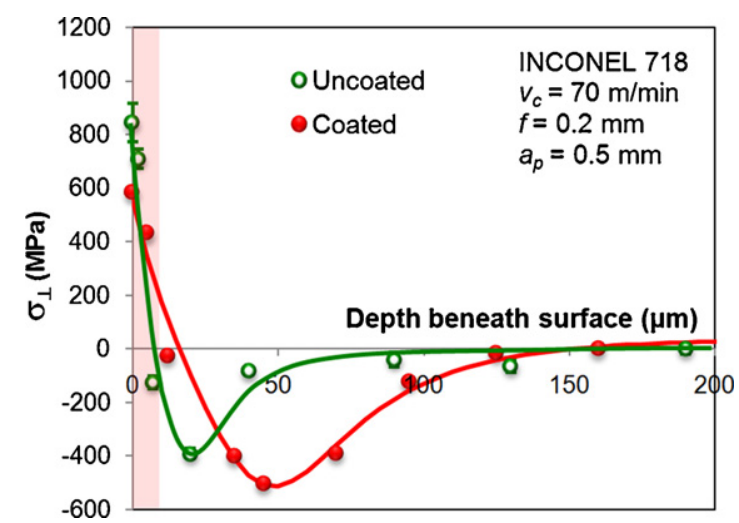

Fig. 6. In-depth $\sigma_{\perp}$ residual stress distribution in machining Inconel 718 .

when compared with the uncoated tools, results in higher residual stresses closer to the surface, which contradicts the present work. However, using the X-ray diffraction technique it is possible to reach a smaller depth than using the hole drilling (typically $10-20 \mu \mathrm{m}$ in hole drilling, and only a few $\mu \mathrm{m}$ by $\mathrm{X}$-ray diffraction). By excluding the first $10 \mu \mathrm{m}$, and comparing the results from Figs. 5 and 6 with those obtained by Sharman et al. [6], it is noted that both results, from the X-ray diffraction and hole drilling, consistently show that the coated tools generate higher residual stresses.

\subsection{Residual stresses in machining AISI $316 \mathrm{~L}$}

For the range of cutting conditions investigated, residual stresses generated by turning AISI 316L are also tensile, and high at the machined surface, although not as high as those obtained by turning Inconel 718. As shown in Fig. 7, both $\sigma_{\|}$and $\sigma_{\perp}$ in-depth residual stresses distributions are similar to those distributions observed when machining Inconel 718.

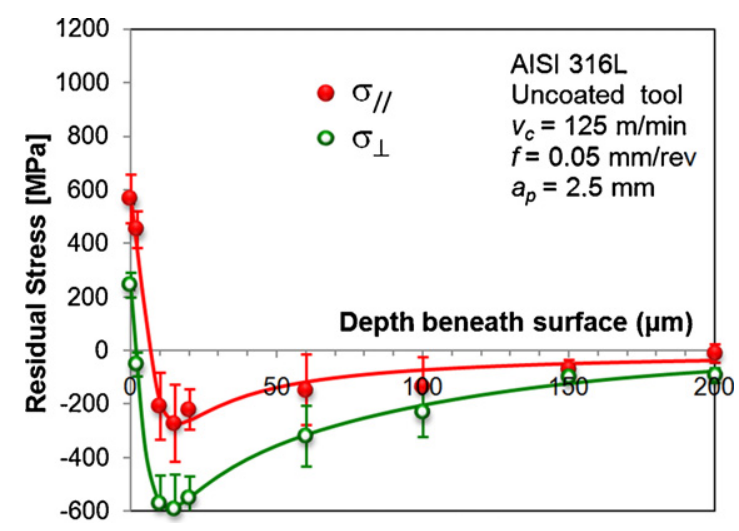

Fig. 7. In-depth residual stresses distributions in machining stainless steel AISI $316 \mathrm{~L}$. 


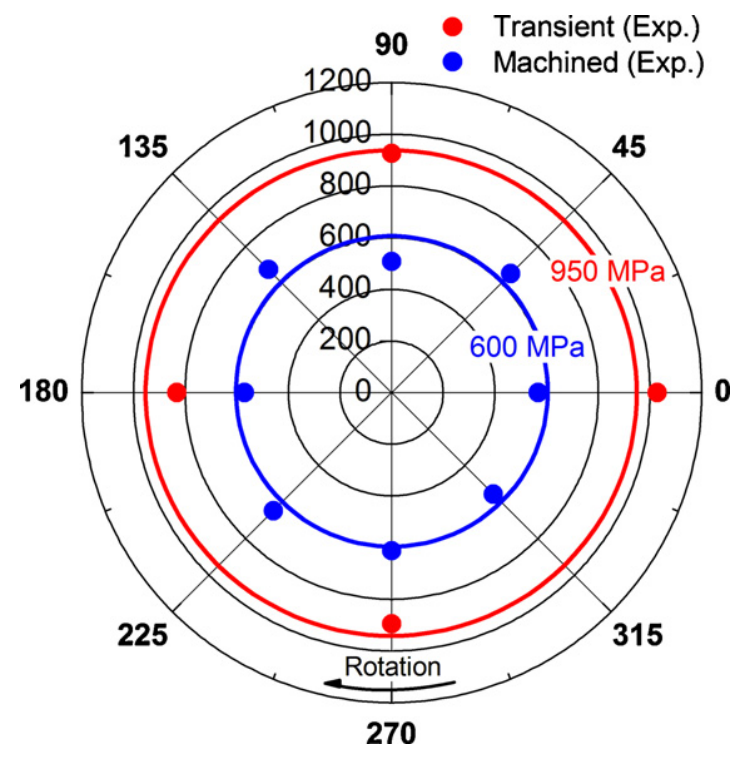

Fig. 8. Experimental $\sigma_{\|}$residual stresses in the transient and machined surfaces at different locations (AISI 316L; T2-uncoated tool; $v_{\mathrm{c}}=125 \mathrm{~m} / \mathrm{min}, f=0.05 \mathrm{~mm} / \mathrm{rev}$ and $a_{\mathrm{p}}=2.5 \mathrm{~mm}$ )

The larger depth of cut used in tuning AISI 316L steel enabled us to measure the residual stresses in the transient surface (the surface between the work surface and the machined surface as shown in Fig. 1). Fig. 8 shows the $\sigma_{\|}$residual stress in the transient and machined surfaces at different locations on these surfaces (from $0^{\circ}$ to $315^{\circ}$ ).

As shown, the residual stress in the transient surface is much larger than that in the machined surface: the average residual stress in the machined surface is about $600 \mathrm{MPa}$ and in the transient surface is about $950 \mathrm{MPa}$. This difference can be due to the variation of the work material behaviour and the tribological conditions resulting from the variation of uncut chip thickness along the tool cutting edge. The tool edge radius has also been observed to vary along the cutting edge, thus making the ratio of edge radius to uncut chip thickness a major factor in the generation of residual stresses. Also, the amount of prior cold working imposed by the tool in the previous passes would affect the work material behaviour and the residual stresses in the subsequent pass [8].

The uncut chip thickness has a strong influence on the residual stresses. These stresses usually increase with the uncut chip thickness [4]. As known, the uncut chip thickness varies along the tool cutting edge, being higher in the transient surface and decreasing as the distance to the nose radius deceases. Therefore, higher stress values should be obtained on the transient surface than on the machined surface. For identical cutting conditions, the residual stresses in the machined surface generated by orthogonal cutting are always greater than those generated by turning $[3,4]$. Also, the residual stresses on the transient surface in turning are close to those found in the machined surface in orthogonal cutting.

\section{Concluding remarks}

This paper presents new knowledge on surface integrity in terms of residual stresses generated in turning of two major difficult-to-machine materials: Inconel 718 and stainless steel AISI 316L. 3D numerical modelling of turning operation provides a good comparison of cutting force $\left(F_{\mathrm{c}}\right)$ and the thermal fields developed. Measured residual stresses on both materials consistently show the appearance of high tensile residual stresses at the machined surface and compressive residual stresses in the sub-surface below 10-25 $\mu \mathrm{m}$. Higher surface residual stresses are generated when machining with the uncoated tool than the coated tool. Also, higher residual stress values were obtained on the transient surface than on the machined surface.

\section{Acknowledgments}

Prof. J.C. Outeiro gratefully acknowledges the financial support from FEDER, through the funding of Project POCI/EME/56406/ 2004, approved by the Fundação para a Ciência e a Tecnologia (FCT) and POCI 2010

\section{References}

[1] Lucca DA, Brinksmeier E, Goch G (1998) Progress in Assessing Surface and Subsurface Integrity. Annals of the CIRP 47(2):669-693.

[2] Matsumoto Y, Hashimoto F, Lahoti G (1999) Surface Integrity Generated by Precision Hard Turning. Annals of the CIRP 48(1):59-62.

[3] M'Saoubi R, Outeiro JC, Changeux B, Lebrun JL, Dias AM (1999) Residual Stress Analysis in Orthogonal Machining of Standard and Resulfurized AISI 316L Steels. Journal of Materials Processing Technology 96(1-3):225-233.

[4] Outeiro JC, Dias AM, Lebrun JL, Astakhov VP (2002) Machining Residua Stresses in AISI 316L Steel and their Correlation with the Cutting Parameters. Machining Science and Technology 6(2):251-270.

[5] Arunachalam RM, Mannan MA, Spowage AC (2004) Surface Integrity When Machining Age Hardened Inconel 718 with Coated Carbide Cutting Tools. International Journal of Machine Tools and Manufacture 44(14):1481-1491.

[6] Sharman AR, Hughes JI, Ridgway K (2006) An Analysis of the Residual Stresse Generated in Inconel 718 When Turning. Journal of Materials Processing Technology 173:359-367.

[7] Liang SY, Su JC (2007) Residual Stress Modeling in Orthogonal Machining. Annals of the CIRP 56(1):65-68.

[8] Outeiro JC, Umbrello D, M'Saoubi R (2006) Experimental and Numerica Modelling of the Residual Stresses Induced in Orthogonal Cutting of AISI 316L Steel. International Journal of Machine Tools and Manufacture 46(14):1786-1794.

[9] Umbrello D, M'Saoubi R, Outeiro JC (2007) The Influence of Johnson-Cook Material Constants on Finite Element Simulation of Machining of AISI 316L Steel. International Journal of Machine Tools and Manufacture 47(3-4):462-470.

[10] Outeiro JC, Dias AM, Lebrun JL (2004) Experimental Assessment of Temperature Distribution in Three-Dimensional Cutting Process. Machining Science and Technology 8(3):357-376.

[11] Noyan IC, Cohen JB (1987) in Society for Experimental Mechanics, (Ed.) Residual Stress-Measurement by Diffraction and Interpretation. Springer-Verlag. NY.

[12] Outeiro JC, Dias AM, Jawahir IS (2006) On the Effects of Residual Stresses Induced by Coated and Uncoated Cutting Tools with Finite Edge Radii in Turning Operations. Annals of the CIRP 55(1):111-116. 